\section{ON THE STUDY OF BIOLOGY}

$\mathrm{T} T$ is my duty to-night to speak about the study of Biology, and while it may be that there are many among you who are quite familiar with that study, yet as a lecturer of some standing, it would, I know by experience, be very bad policy on my part to suppose such to be extensively the case. On the contrary, I must imagine that there are many of you who would like to know what Biology is; that there will be others who have that amount of information, but would nevertheless gladly learn why it should be worth their while to study Biology ; and yet others, again, to whom these two points are clear, but who desire to learn how they had best study it, and finally when they had best study it; and I shall address myself to the endeavour to give you some answer to these four questions-what Biology is, why it should be studied, how it should be studied, and when it should be studied.

In the first place, in respect to what Biology is, there are, I believe, some persons who imagine that the term "Biology" is simply a new-fangled denomination, a neologism in short, for what used to be known under the title of "Natural History," but I shall try to show you, on the contrary, that the word is the expression of the growth of science during the last 200 years, and came into existence half a century ago.

At the revival of learning, knowledge was divided into two kinds-the knowledge of nature and the knowledge of man; for it was the current idea then (and a great deal of that ancient conception still remains) that there was a sort of essential antithesis, not to say antagonism, between nature and man ; and that the two had not very much to do with one another, except that the one was oftentimes exceedingly troublesome to the other. Though it is one of the salient merits of our great philosophers of the scventeenth century, that they recognise but one scientific method, applicable alike to man and to nature, we find this notion of the existence of a broad distinction between nature and man in the writings of Bacon and Hobbes of Malmesbury; and I have brought with me that famous work which is now so little known, oreatly as it deserves to be studied, "The Leviathan," in order that I may put to you in the wonderfully terse and clear language of Thomas Hobbes, what was his view of the matter. He says :--

"The register of knowledye of fact is called history. Whereof there be two sorts, one called natural history; which is the history of such facts or effects of nature as have no dependence on man's will ; such as are the histories of metals, plants, animals, regions, and the like. The other is civil history ; which is the history of the voluntary actions of men in commonwealths."

So that all history of fact was divided into these two great groups of natural and of civil history. The Royal Society was in course of foundation about the time that Hobbes was writing this book, which was published in $165 \mathrm{I}$, and that Society is termed a "Society for the Advancement of Natural Knowledge," which is nearly the same thing as a "Society for the Advancement of Natural History." As time went on, and the various branches of human knowledge became more distinctly developed and separated from one another, it was found that some were much more susceptible of precise mathematical treatment than others. The publication of the "Principia" of Newton, which probably gave a greater stimulus to physical science than any work ever published before, or which is likely to be published hereafter, showed that precise mathematical methods were applicable to those branches of science such as astronomy, and what we now call physics, which occupy a very large portion of the domain of what the older writers understood by natural history. And inasmuch as the partly deductive and partly

I A lecture by Prof. Huxley, delivered at the South Kensington Museum on Saturday, December 16, 1876 . experimental methods of treatment to which Newton and others subjected these branches of human knowledge, showed that the phenomena of nature which belonged to them were susceptible of explanation, and thereby came within the reach of what was called "philosophy" in those days; so much of this kind of knowledge as was not included under astronomy came to be spoken of as "natural philosophy"-a term which Bacon had employed in a much wider sense. Time went on, and ret other branches of science developed themselves. Chemistry took a definite shape, and as all these sciences, such as astronomy, natural philosophy, and chemistry, were susceptible either of mathematical treatment or of experimental treatment, or of both, a great distinction was drawn between the experimental branches of what had previously been called natural history and the observational branches -those in which experiment was (or appeared to be) of doubtful use, and where, at that time, mathematical methods were inapplicable. Under these circumstances the old name of "Natural History" stuck by the residuum, by those phenomena which were not, at that time, susceptible of mathematical or experimental treatment; that is to say, those phenomena of nature which come now under the general heads of physical geography, geology, mineralogy, the history of plants, and the history of animals. It was in this sense that the term was understood by the great writers of the middle of the last century -Buffon and Linnæus-by Buffon in his great work, the "Histoire Naturelle Générale," and by Linnæus in his splendid achievement, the "Systema Naturæ." The subjects they deal with are spoken of as "Natural History," and they called themselves and were called "Naturalists." But you will observe that this was not the original meaning of these terms; but that they had, by this time, acquired a signification widely different from that which they possessed primitively.

The sense in which "Natural History" was used at the time I am now speaking of has, to a certain extent, endured to the present day. There are now in existence, in some of our northern universities, chairs of "Civil and Natural History" in which "Natural History" is used to indicate exactly what Hobbes and Bacon meant by that term. There are others in which the unhappy incumbent of the chair of Natural History is, or was, still supposed to cover the whole ground of geology and mineralogy, zoology, perhaps even botany in his lectures. But as science made the marvellous progress which it did make at the latter end of the last and the beginning of the present century, thinking men began to discern that under this title of "Natural History" there were included very beterogeneous constituents-that, for example, geology and mineralogy were, in many respects, widely different from botany and zoology; that a man might obtain an extensive knowledge of the structure and functions of plants and animals without having need to enter upon the study of geology and mineralogy, and vice versâ; and, further, as knowledge advanced, it became clear that there was a great analogy, a very close alliance, between those two sciences of botany and zoology which deal with living beings, while they are much more widely separated from all other studies. It is due to Buffon to remark that he clearly recognised this great fact. He says: "ces deux genres d'êtres organisés [les animaux et les végétaux] ont beaucoup plus de propriétés communes que de différences réelles." Therefore, it is not wonderful that, at the beginning of the present century, and oddly enough in two different countries, and so far as I know, without any intercommunication, two famous men clearly conceived the notion of uniting the sciences which deal with living matter into one whole, and of dealing with them as one discipline. In fact I may say there were three men to whom this idea occurred contemporaneously, although there were but two who carried it into effect, and only one who worked it out completely. The persons to M 2 
whom I refer were the eminent physiologist Bichat, the great naturalist Lamarck, in France; and a distinguished German, Treviranus. Bichat ${ }^{1}$ assumed the existence of a special group of "physiological" sciences. Lamarck, in a work published in $18 \mathrm{cr},{ }^{2}$ for the first time made use of the name "Biclogie" from the two Greek words which signify a discourse upon life and living things. About the same time, it occurred to Treviranus that all those sciences which deal with living matter are essentially and fundamentaliy one, and ought to be treated as a whole, and, in the year I 802 , he published the first volume of what he also called "Biologie." Treviranus's great merit consists in this, that he worked out his idea, and wrote the very remarkable book to which I refer. It consists of six volumes, and occupied its author for twenty years-from 1802 to 1822

That is the origin of the term "Biology," and that is how it has come about that all clear thinkers and lovers of consistent nomenclature have substituted for the old confusing name of "Natural History," which has conveyed so many meanings, the term "Biology" which denotes the whole of the sciences which deal with living things, whether they be animals or whether they be plants. Some little time ago--in the course of this year, I think-I was favoured by a learned classic, Dr. Field of Norwich, with a disquisition, in which he endeavoured to prove that, from a philological point of view, neither Treviranus nor Lamarck had any right to coin this new word "Biology" for their purpose ; that, in fact, the Greek word "Bios" had relation only to human life and human affairs, and that a different word was employed when they wished to speak of the life of animals and plants. So Dr. Field tells us we are all wrong in using the term biology, and that we ought to employ another, only unluckily he is not quite sure about the propriety of that which he proposes as a substititte. It is a somewhat hard one-zootocology. I am sorry we are wrong, because we are likely to continue so. In these matters we must have some sort of "Statute of limitations." When a name has been employed for lralf-a-century, persons of authority ${ }^{3}$ have been using it, and its sense has become well understood, I an afraid that people will go on using it, whatever the weight of phrilological objection.

Now that we have arrived at the origin of this word "Biology," the next point to consider is : What ground does it cover? I have said that in its strict technical sense it covers all the phenomena that are exhibited by living things, as distinguished from those which are not livirig; but while that is all very well so long as we confine ourselves to the lower animals and to plants, it lands us in a very considerable difficulty when we reach the higher forms of living things. For whatever view we may entertain about the nature of man, one thing is perfectly certain, that he is a living creature. Hence, if our definition is to be interpreted strictly, we must include man and all his ways and works under the head of Biology ; in which case we should find that psychology, politics, and political economy, would be absorbed into the province of Biology. In fact, civil history would be merged in natural history. In strict logic it may be hard to object to this course, because no one can doubt that the rudiments and cutlines of our own mental phenomena are traceable among the lower animals. They have their economy and their polity, and if, as is always admitted, the polity of bces and the commonwealth of wolves fall within the purview of the biologist proper, it becomes hard to say why we should not include therein human affairs, which in so many cases resemble those of the bees in

See the distinction between the "sciences physiques" and the "sciences physiologiques" in the "Anatomie Générale," xor.

"Hydrogeologie," an. $x$. (I81)

"The term Biology, which neans exactly what we wish to express, the sivence of Life, has often been used and has of late become not uncommon, among good writers."-Whewell, "Philosophy of the Inductive Sciences," visl. i. p. 544 (edition of 7847 ) zealous getting, and are not without a certain parity in the proceedings of the wolves. The real fact is that we biologists are a self-sacrificing people; and inasmuch as, on a moderate estimate, there are about a quarter of a million different species of animals and plants to know about already, we feel that we have more than sufficient territory. There has been a sort of practical convention by which we give up to a different branch of science what Bacon and Hobbes would have crlled "Civil History." That branch of science has constituted itself under the head of Sociology. I may use phraseology which at present will be well understood and say that we have allowed that province of Biology to become autonomous; but I should like you to recollect that that is a sacrifice, and that you should not be surprised if it occasionally happens that you see a biologist trespassing upon questions of philosophy or politics; or meddling with human education; because, after all, that is a part of his kingdom which he has only voluntarily forsaken.

Having now defined the meaning of the word Biology, and having indicated the general scope of Biological Science, I turn to my second question, which isWhy should we study Biology? Possibly the time may cone when that will seem a very odd question. That we, living creatures, should not feel a certain amount of interest in what it is that constitutes our life will eventually, under altered ideas of the fittest objects of human inquiry, seem to be a singular phenorienon; but at piesent, judging by the practice of teachers and educators, this would seem to be a matter that does not concern us at all. I propose to put before you a few considerations which I dare say many of you will be familiar with already, but which will suffice to show-not fully, because to demonstrate this point fully would take a great many lecturesthat there are some very good and substantial reasons why it may be advisable that we should know something about this branch of human learning. I myself entirely agree with another sentiment of the philosopher of Malmesbury, "that the scope of all speculation is the performance of some action or thing to be done," and I have not any yery great respect for, or interest in, mere knowing as such. I judge of the value of human pursuits by their bearing upon human interests; in orher words, by their utility, but I should like that we should quite clearly understand what it is that we mean by this word "utility." Now in an Englishman's mouth it generally means that by which we get pudding or praise, or both. I have no doubt that is one meaning of the word utility, but it by no means includes all I mean by utility. I think that kilowledge of every kind is useful in proportion as it tersds to give people right ideas, which are essential to the foundation of right practice, and to remove wrong ideas, which are the no less essential foundations and fertile mothers of every description of error in practice. And inasmuch as, whatever practical people may say, this world is, after all, absolutely governed by ideas, and very often by the wildest and most hypothetical ideas, it is a matter of the very greatest importance that our theories of things, and even of things that seem a long way apart from our daily lives, should be as far as possible true, and as far as possible removed from error. It is not only in the coarser practical sense of the word "utility," but in this higher and broader sense that I measure the value of the study of biology by its utility, and I shall try to point out to you that you will feel the need of some knowledge of biology at a gieat many turns of this present nineteenth century life of ours. For example, most of us lay great and very just stress, upon the conception which is entertained of the position of man in this universe and his relation to the rest of nature. We have almost all of us been told, and most of us hold by the tradition, that man occupies an isolated and peculiar position in nature; that though he is in the world he is not of the world; that his relations to things 
about him are of a remote character, that his origin is recent, his duration likely to be short, and that he is the great centrai figure round which other things in this world revolve. But this is not what the biologist tells us. At the present moment you will be kind enough to separate me from them, because it is in no way essential to my argument just now that I should advocate their views. Don't suppose that I am saying this for the purpose of escaping the responsibility of their beliefs, because at other times and in other places I do not think that point has been left doubtful ; but I want clearly to point ont to you that for my present argument they may all be wrong ; nevertheless, my argument will hold good. The biologists atells us that all this is an entire mistake. They turn to the physical organisation of man. They examine his whole structure, his bony frame, and all that clothes it. They resolve him into the finest particles into which the microscope will enable them to break him up. They consider the performance of his various functions and activities, and they look at the manner in which be occurs on the surface of the world. Then they turn to other animals and taking the first handy domestic animal-say a dog-they profess to be able to demonstrate that the analysis of the dog leads them, in gross, to precisely the same results as the analysis of the man; that they find almost identically the same bones, having the same relations; that they can name the muscles of the dog by the names of the muscles of the man, and the nerves of the dog by those of the nerves of the man, and that such structures and organs of sense as we find in the man such also we find in the dog; they analyse the brain and spinal cord, and they find that the nomenclature which fits the one answers for the other. They carry their microscopic inquiries in the case of the dog as far as they can, and they find that his body is resolvable into the same elements as those of the man. Moreover, they trace back the dog's and the man's development, and they find that, at a certain stage of their existence, the two creatures are not distinguishable the one from the other; they find that the dog and his kind have a certain distribution over the surface of the world comparable in its way to the distribution of the human species. What is true of the dog they tell us is true of all the higher animals; and they assert that for the whole of these creaiures they can lay down a common plan, and regard the man and the dog, and the horse and the ox as minor modifications of one great fundamental unity. Moreover, the investigations of the last three-quarters of a century have proved, they tell us, that similar inquiries carried out through all the different kinds of animals which are met with in nature will lead us, not in one straight series, but by many roads, step by step, gradation by gradation, from man, at the summit, to specks of anirnated jelly at the bottom of the series; so that the idea of Leibnitz and of Bonnet, that animals form a great scale of being, in which there are a series of gradations from the most complicated form to the lowest and simplest; that idea, though not exactly in the form in which it was propounded. by those philosophers, turns out to be substantially correct. More than this, when biologists pursue their investigations into the veretable world, they find that they can, in the same way, follow out the structure of the plant from the most gigantic and complicated trees down, through a similar series of gradations, until they arrive at specks of animated jelly, which they are puzzled to distinguish from those specks which they reached by the animal road.

Thus, biologists have arrived at the conclusion that a fundamental uniformity of structure pervades the animal and vegetable worlds, and that plants and animals differ from one another simply as modifications of the same great general plan.

Again, they tell us the same story in regard to the study of function. They admit the large and important interval which, at the present time, separates the manifesta- tions of the mental faculties observable in the higher forms of mankind, and even in the lower forms, such as we know them, mentally from those exhibited by other animals; but, at the same time, they tell us that the foundations or rudiments of almost all the faculties of man are to be met with in the lower animals; that there is a unity of mental faculty as well as of bodily structure, and that, here also, the difference is a difference of degree and not of kind. I said "almost all," for a reason. Among the many distinctions which have been drawn between the lower creatures and ourselves, there is one which is hardly ever insisted on, ${ }^{1}$ but which may be very fitly spoken of in a place so largely devoted to art as that in which we are assembled. It is this, that while among various kinds of animals it is possible to discover traces of all the other faculties of man, especially the faculty of mimicry, yet that particular form of mimicry which shows itself in the imitation of form either by modelling or by drawing is not to be met with. As far as I know, there is no sculpture or modelling, and decidedly no painting or drawing, of animal origin. I mention the fact, in order that such comfort may be derived therefrom as artists may feel inclined to take.

If what the biologists tell us is true, it will be needful for us to get rid of our erroneous conceptions of man and of his place in nature, and substitute right ones for them. But it is impossible to form any judgment as to whether the biologists are right or wrong unless we are able to appreciate the nature of the arguments which they have to offer.

One would almost think that this was a self-evident proposition. I wonder what a scholar would say to the man who should undertake to criticise a difficult passage in a Greek play but who obviously had not acquainted himself with the rudiments of Greek grammar. And yet before giving positive opinions about these high questions of Biology people not only don't seem to think it necessary to be acquainted with the grammar of the subject, but they have not even mastered the alphabet. You find criticism and denunciation showered about by persons who not only have not attempted to go through the discipline necessary to enable them to be judyes, but have not even reached that stage of emergence from ignorance in which the knowledge that such a discipline is necessary dawns upon the mind. I have had to watch with some attention-in fact I have been favoured with a good deal of it myself-the sort of criticism with which biologists and biological teachings are visited. I am told every now and then that there is a "brilliant article" 2 in so-and-so, in which we are all demolished. I used to read these things once, but I am getting old now, and I have ceased to attend very much to this cry of "wolf." When one does read any of these productions, what one finds generally, on the face of it, is that the brilliant critic is devoid of even the elements of biological knowledge, and that his brilliancy is like the light given out by the crackling of thorns under a pot of which Solomon speaks. So far as I recollect Solomon makes use of that image for purposes of comparison; but I won't proceed further into that matter.

Two things must be obvious : in the first place, that every man who has the interests of truth at heart must earnestly desire that every well-founded and just criticism that can be made should be made ; but that, in the second place, it is essential to anybody's being able to benefit by criticism that the critic should know what he is talking about and be in a position to form a mental image of the facts symbolised by the words he uses. If not, it is as obvious in the case of a biological argument as it is in that

I think that Prof. Allman was the first to draw attention to it.

2 Galileo was troubled by a sort of people whom he called "paper philosophers," because they fancied that the true reading of nature was to be detected by the collation of texts. The race is not extinct, but, as of old brings forth its " winds of doctrine" by which the weathercock heads among us are much exercised. 
of a historical or philological discussion, that such criticism is a mere waste of time on the part of its author, and wholly undeserving of attention on the part of those who are criticised. Take it then as an illustration of the importance of biological study, that thereby alone are men able to form sometbing like a rational conception of what constitutes valuable criticism of the teachings of biologists. ${ }^{\text {I }}$

Next, I may mention another bearing of biological knowledge-a more practical one in the ordinary sense of the word. Consider the theory of infectious disease. Surely that is of interest to all of us. Now the theory of infectious disease is rapidly being elucidated by biological study. It is possible to produce from among the lower animals cases of devastating diseases which have all the zppcarance of our infectious diseases, and which are certainly and unmistakably caused by living organisms. This fact renders it possible, at any rate, that that doctrine of the causation of infectious disease which is known under the name of "the germ theory" may be well-founded; and if so it must needs lead to the most important prac-ical measures in dealing with those most terrible visitations. It may be well that the general as well as the professional public should have a sufficient knowledge of biological truths to be able to take a rational interest in the discussion of such problems, and to see, what I think they may hope to see, that, to those who possess a sufficient elemertary knowledge of Biology, they are not all quite open questions.

Let me mention another important practical illustration of the value of biological study. Within the last forty years the theory of agriculture has been revolutionised. The researches of Liebig, and those of our own Lawes and Gilbert, have had a bearing upon that branch of industry the importance of which cannot be over-estimated; but the whole of these new views have grown out of the better explanation of certain processes which go on in plants, and which of course form a part of the subjectmatter of Biology.

I might go on multiplying these examples, but I see that the clock won't wait for me, and I must therefore pass to the third question to which I referred:-Granted that Biology is something worth studying, what is the best way of studying it? Here I must point out that, since Biology is a physical science, the method of studying it must needs be analogous to that which. is followed in the other physical sciences. It has now long been recognised that if a man wishes to be a chemist it is not only necessary that he should read chemical books and attend chemical lectures, but that he should actually for himself perform the fundamental experiments in the laboratory, and know cxactly what the words which he finds in his books and hears from his teachers, mean. If he does not do that be may read till the crack of doom, but ke will never know much about chemistry. That is what every chemist will tell you, and the physicist will do the same for his branch of science. The great changes and improvements in physical and chemical scientific education which have taken place of late have all resulted from the combination of practical teaching with the reading of books and with the hearing of lectures. The same thing is true in Biology. Nobody

I Some critics do not even rake the trouble to read. I have recently been adjured with much solemnity, to state publicly why I have "changed "my evolution.

To this my reply is, Why should I when that statement was made seven To this my reply is, Why should when that statement was made seven years ago? An address delivered rom the lrublic document, inasnuch as it gical Society in 1870 may be said to be a puislic document, inamuch as it not only appeared in the fournat of that learned body, but was re-published in 1873 in a volume of "Critutes and Addresses, to which my nanie is attached. Therein will be founil a pretty full statement of niy reasons for entunciating two propositions: (I) that " when we turn to the higher Vertebrate, the results of recent investigations, however we may sift and criticise them, seem to me to leave a clear balance du favolir of the evolution of iving forms one from another:" and (2) that the case of the horse is one which "will stand rigorous criticism.

Thus I do not see clearly in what way I can be said to have changed my opinion, except in the way of intensifying it, when in consequence of the evolution as not worth serious consideration. will ever know anything about Biology except in a dilettante "paper-philosopher" way, who contents himself with reading books on botany, zoology, and the like; and the reason of this is simple and easy to understand. It is that all language is merely symbolical of the things of which it treats; the more complicated the things, the more bare is the symbol, and the more its verbal definition requires to be supplemented by the information derived directly from the handling, and the seeing, and the touching of the thing symbolised:- that is really what is at the bottom of the whole matter. It is plain common sense, as all truth, in the long run is only common sense clarified. If you want a man to be a tea merchant, you don't tell him to read books about China or about tea, but you put him into a tea-merchant's office where he has the handling, the smelling, and the tasting of tea. Without the sort of knowledge which can be gained only in this practical way his exploits as a tea merchant will soon come to a bankrupt termination. The "paper-philosophers" are under the delusion that physical science can be mastered as literary accomplishments are acquired, but unfortunately it is not so. You may read any quantity of books, and you may be almost as ignorant as you were at starting, if you don't have, at the back of your minds, the change for words in definite images which can only be acquired through the operation of your observing faculties on the phenomena of nature.

It may be said:- " That is all very well, but you told us just now that there are probably something like a quarter of a million different kinds of living and extinct animals and plants, and a human life could not suffice for the examination of one-fiftieth part of all these." That is true, but then comes the great convenience of the way things are arranged; which is, that although there are these inmense numbers of different kinds of living things in existence, yet they are built up, after all, upon marvellously few plans.

There are, I suppose, about 100,000 species of insects, if not more, and yet anybody who knows one insect--if a properly chosen one-will be able to have a very fair conception of the structure of the whole. I do not mean to say he will know that structure thoroughly or as well as it is desirable he should know it, but he will have enough real knowledge to enable him to understand what he reads, to have genuine images in his mind of those structures which become so variously modified in all the forms of insects he has not seen. In fact, there are such things as types of form among animals and vesgetables, and for the purpose of getting a definite knowledge of what constitures the leading modifications of animal and plant life it is not needful to exarnine more than a comparatively small number of animals and plants.

Let me tell you what we do in the biological laboratory in the building adjacent to this. There I lecture to a class of students daily for about tour-and-a-half montlis, and my class have, of course, their text-books; but the essential part of the whole teaching, and that which I regard as really the most important part of it, is a laboratory for practical work, which is simply a room with all the materials arranged for ordinary dissection. We have tables properly arranged in resard to light, microscopes, and dissecting instruments, and we work through the structure of a certain number of animals and plants. As, for example, among the plants, we take a yeast plant, a Protococcus, a common mould, a Charra, a fern, and some flowering plant; among animals we examine such things as an amæeba, a corticella, and a fresh-water polype. We dissect a star-fish, an earthworm, a snail, a squid and a fresh-water mussel. We examine a lobster and a cray-fish, and a black beetle. We go on to a common skate, a cod-fish, a frog, a tortoise, a pigeon, and a rabbit, and that takes us about all the time we have to give. The purpose of this course is not to make skilled dissectors, but to give every student a clear 
and definite conception, by means of sense-images, of the characteristic structure of each of the leading modifications of the animal kingdom; and that is perfectly possible, by going no further than the length of that list of forms which I have enumerated. If a man knows the structure of the animals I have mentioned, he has a clear and exact, however limited, apprehension of the essential features of the organisation of all those great divisions of the animal and vegetable kingdoms to which the forms I have mentioned severally belong. And it then becomes possible for him to read with profit, because every time he meets with the name of a structure, he has a definite image in his mind of what the name means in the particular creature he is reading about, and therefore the reading is not mere reading. It is not mere repetition of words; but every term employed in the description, we will say, of a horse or of an elephant, will call up the image of the things he had seen in the rabbit, and he is able to form a distinct conception of that which he has not seen as a modification of that which he has seen.

find this system to yield excellent results; and I have no hesitation whatever in saying, that any one who has gone through such a course, attentively, is in a better position to form a conception of the great truths of Biology, especially of morphology (which is what we chiefly deal with), than if he had merely read all the books on that topic put together.

The convection of this discourse with the Loan Colleciion of Scientific Apparatus arises out of the exhibition in that collection of certain aids to our laboratory work. Sucii of you as have visited that very interesting collection may have roticed a series of diagrams and of preparations illustrating the structure of a frog. Those diagrams and preparations have been made for the use of the students in the biological laboratory. Similar diagrams and prenarations illustrating the structure of all the other forms of life we examine, are either made or in course of preparation. Thus the student has before him, first, a picture of the structure he ought to see, secondly, the structure itself worked out; and if with these aids, and such needful explanations and practica! hints as a demonstrator can supply, he cannot make out the facts for himself in the materials suppiied to him, he had better take to some other pursuit than that of biological science.

I should have been glad to have said a few words about the use of museums in the study of Biology, but I see that my time is becoming short, and I have yet another question to answer. Nevertheless I must, at the risk of wearying you, say a word or two upon the important subject of museums. Without doubt there are no helps to the study of Biology, or rather to some branches of it, which are, or may be, more important than natural history museums; but, in order to take this place in regard to Biology, they must be museums of the future. The museumis of the present do not do by any means so much for us as they might do. I do not wish to particularise, but $I$ dare say many of you seeking knowledge, or in the laudable desire to employ a holiday usefully, have visited some great natural history museum. You have walked throush a quarter of a mile of animals more or less well stuffed, with their long names written out underneath them, and, unless your experience is very different from that of most people, the upshot of it all is that you leave that splendid pile with sore feet, a bad headache, and a general idea that the animal kingdom is a "mighty maze without a plan." I do not think that a museum which brings about this result does all that may be reasonably expected of such an institution. What is needed in a collection of natural history is that it should be made as accessible and as useful as possible, on the one hand to the general public, and on the other to scientific workers. That need is not met by constructing a sort of happy hunting-ground of miles of glass cases, and, under the pretence of exhibiting everything, putting the maximum amount of obstacle in the way of those who wish properly to see anything.

What the public want is easy and unhindered access to such a collection as they can understand and appreciate; and what the men of science want is similar access to the materials of science. To this end the vast mass of objects of natural history should be divided into two parts-one open to the public, the other to men of science, every day. The former division should exemplify all the more important and interesting forms of life. Explanatory tablets should be attached to them, and catalogues containing clearly-written popular expositions of the general significance of the objects exhibited should be provided. The latter should contain, packed into a comparatively small space, in rooms adapted for working purposes, the objects of purely scientific interest. For example, we will say I am an ornithologist. I go to examine a collection of birds. It is a positive nuisance to have them stuffed. It is not only sheer waste, but $I$ have to reckon with the ideas of the bird-stuffer, while, if I have the skin and nobody has interfered with it I can form my own judgment as to what the bird was like. For ornithological purposes what is needed is not glass cases full of stuffed birds on perches, but convenient drawers into each of which a great quantity of skins will go. They occupy no great space and do not require any expenditure beyond their original cost. But for the purpose of the public, who want to learn indeed, but do not seek for minute and technical knowledge, the case is different. What one of the general public walking into a collection of birds desires to see is not all the birds that can be got together. He does not want to compare a hundred species of the sparrow tribe side by side; but he wishes to know what a bird is, and what are the great modifications of bird structure, and to be able to get at that knowledge easily. What will best serve his purpose is a comparatively small number of birds carefully selected, and artistically, as well as accurately, set up; with their different ages, their nests, their young, their eggs, and their skeletons side by side; and in accordance with the admirable plan which is pursued in this museum, a tablet, telling the spectator in legible characters what they are and what they mean. For the instruction and recreation of the public such a typical collection would be of far greater value than any many-acred imitation of Noah's ark.

Lastly comes the question as to when biological study may best be pursued. I do not see any valid reason why it should not be made, to a certain extent, a part of ordinary school training. I have long advocated this view, and I am perfectly certain that it can be carried out with ease, and not only with ease, but with very considerable profit to those who are taught; but then such instruction must be adapted to the minds and needs of the scholars. They used to have a very odd way of teaching the classical languages when I was a boy. The first task set you was to learn the rules of the Latin grammar in the Latin language-that being the language you were going to learn! I thought then that this was an odd way of learning a language, but did not venture to rebel against the judgment of my superiors. Now, perhaps, I am not so modest as I was then, and I allow myself to think that it was a very absurd fashion. But it would be no less absurd if we were to set about teaching Biology by putting into the hands of boys a series of definitions of the classes and orders of the animal kingdom, and making them repeat them by heart. That is a very favourite method of teaching, so that I sometimes fancy the spirit of the old classical system has entered into the new scientific system, in which case I would much rather that any pretence at scientific teaching were abolished altogether. What really has to 
be done is to get into the young mind some notion of what animal and vegetable life is. You have to consider in this matter practical convenience as well as other things. There are difficulties in the way of a lot of boys making messes with slugs and snails; it might not work in practice. But there is a very convenient and handy animal which everybody has at hand, and that is himself; and it is a very easy and simple matter to obtain common plants. Hence the broader facts of anatomy and physiology can be taught to young people in a very real fashion by dealing with the broad facts of human structure. Such viscera as they cannot very well examine in themselves, such as hearts, lungs, and livers, may be obtained from the nearest butcher's shop. In respect to teaching something about the biology of plants, there is no practical difficulty, because almost any of the common plants will do, and plants do not make a mess-at least they do not make an unpleasant mess; so that, in my judgment, the best form of Biology for teaching to very young people is elementary human physiology on the one hand, and the elements of botany on the other; beyond that $I$ do not think it will be feasible to advance for some time to come. But then I see no reason why in secondary schools, and in the Science Classes which are under the control of the Science and Art Department-and which I may say, in passing, have, in my judgment, done so very much for the diffusion of a knowledge over the country-I think that in those cases we may go further, and we may hope to see instruction in the elements of Biology carried out, not perhaps to the same extent, but still upon somewhat the same principle as wc do here. There is no difficulty, when you have to deal with students of the ages of 15 or 16 , in practising a little dissection and getting a notion, at any rate, of the four or five great modifications of the animal form, and the like is true in regard to plants.

While, lastly, to all those who are studying biological science with a view to their own edification merely, or with the intention of becoming zoologists or botanists ; to all those who intend to pursue physiology-and especially to those who propose to employ the working years of their lives in the practice of medicine-I say that there is no training so fitted, or which may be of such important service to thcm, as the thorough discipline in practical biological work which I have sketched out as being pursued in the laboratory hard by.

I may add that, beyond all these different classes of persons who may profit by the study of Biology, there is yet one other. I remember, a number of years ago, that a gentleman who was a vehement opponent of Mr. Darwin's views and had written some terrible articles against them, applied to me to know what was the best way in which he could acquaint himself with the strongest arguments in favour of evolution. I wrote back, in all good faith and simplicity, recommending him to go through a course of comparative anatomy and physiology, and then to study development. I am sorry to say he was very much dis. pleased, as people often are with good advice. Notwithstanding this discouraging result, I venture, as a parting word, to repeat the suggestion, and to say to all the more or less acute lay and clerical "paper-philosophers" I who venture into the regions of biological controversy-Get a little sound, thorough, practical, elementary instruction in biology.

\section{T. H. HuXLEY}

$x$ Writers of this stamp are fond of talking about the Baconian method. beg them therefore to lay to heart these two weighty sayings of the herald of Modern Science :-

Syllogisums ex propositionibus constat, propositiones ex verbis, verba notionum tesseræ sunt. Itaque si notiones ipsa (id quod basis rei est) conjusa sint et temere a rebus abstractax, nihil in is qua superstruuntur es " movum Organon," il. I4

in ut in primo capitulo Geneseos et in libro Job et aliis scripturis sacris, philo sophiam naturalem fundare conati sint ; inter vivos querentes moriwa." lbid., 65.
EXPERIMENTS WITH THE RADIOHETER

I.

A BSTRACTS of my earlier papers on "Repulsion A Resulting from Radiation" having appeared in NATURE, it has been suggested that an account of my later researches, which place the subject in such a different light, may also prove of interest.

It has already been shown that if the air is expelled from a large bulb containing a suspended bar of pith, and a lighted candle is placed about 2 inches from the globe, the pith bar commences to oscillate to and fro, the swing gradually increasing in amplitude until the dead centre is passed over, when several complete revolutions are made. The torsion of the suspended fibre now offers resistance to the revolutions, and the bar commences to turn in the opposite direction. It has been found, however, that very little movement takes place until the vacuum is so good as to be almost beyond the powers of an ordinary air-pump to produce, and that, as the vacuum gets more nearly absolute, so the force increases in power. The most obvious explanation therefore is, that the repulsive action is due to radiation; but at a very early stage of my investigation I found that the best vacuum I had succeeded in producing might contain enough matter to offer resistance to motion, and in describing an experiment in a paper sent to the Royal Society on February 5, 1876 , I said that the impression conveyed to my mind was that the torsion beam was swinging in a viscous fluid, and the repulsion caused by radiation was indirectly due to a difference of thermometric heat between the black and white surfaces of the moving body, and that it might be due to a secondary action on the residual gas.

I have recently succeeded in producing such a complete exhaustion that I have not only reached the point of maximum effect, but gone so far beyond it that repulsion nearly ceases, and the results I have thus obtained seem to show conclusively that the true explanation of the action of the radiometer is that given by Mr. Johnstone Stoney, according to which the repulsion is due to the internal movements of the molecules of the residual gas. When the mean length of path between successive collisions of the molecules is small compared with the dimensions of the vessel, the molecules, rebounding from the heated surface, and therefore moving with an extra velocity, help to keep back the more slowly moving molecules which are advancing towards the heated surface; it thus happens that though the individual kicks against the heated surface are increased in strength in consequence of the heating, yet the number of molecules struck is diminished in the same proportion, so that there is equilibrium on the two sides of the discs, even though the temperature of the faces are unequal. But when the exhaustion is carried to so high a point that the molecules are sufficiently few, and the mean length of path between their successive collisions is comparable with the dimensions of the vessel, the swiftly-moving, rebounding molecules spend their forces in part or in whole on the sides of the vessel; and the onward crowding, more slowly-moving molecules are not kept back as before, so that the number which strike the warmer face approaches to, and in the limit equals, the number which strike the back cooler face; and as the individual impacts are stronger on the warmer than on the cooler face, pressure is produced, causing the warmer face to retreat.

Before referring at length to the experiments which led to my adopting the above theory, I will describe some effects of dark heat, \&c., on the radiometer. In a paper I sent to the Royal Society on January 5, I876, and which is now being published in the Philosophical Transactions of the Royal Society, about seventeen pages are occupied with the description of my experiments with various forms of this instrument. In the present paper I propose only to refer to a few typical experiments made during the year 1875 . 